\title{
Rank reversals in tree growth along tree size, competition and climatic gradients for four forest canopy dominant species in Central Spain*
}

\author{
David SÁncheZ-GómeZ ${ }^{1,2}$, Miguel A. ZAVAla ${ }^{1,2 * *}$, Daniël B. VAN SchaLKWIJK ${ }^{3}$, Itziar R. URBIETA ${ }^{1,4}$, \\ Fernando VALLADARES ${ }^{5,6}$
}

\author{
${ }^{1}$ Departamento de Ecología, Universidad de Alcalá, Edificio de Ciencias, Ctra. Madrid-Barcelona km 33.6, E-28871 Alcalá de Henares, Spain \\ ${ }^{2}$ Centro de Investigación Forestal (CIFOR), INIA, Crta. Coruña Km 7,5, E-28040 Madrid, Spain \\ ${ }^{3}$ Netherlands Organisation for Applied Scientific Research (TNO) Quality of Life, Business Unit Biosciences / Leiden Amsterdam Centre \\ for Drug Research, PO Box 360 (PP 8), 3700 AJ, Zeist, The Netherlands \\ ${ }^{4}$ Instituto de Recursos Naturales y Agrobiología, CSIC, PO Box 1052, E-41080 Sevilla, Spain \\ ${ }^{5}$ Instituto de Recursos Naturales, Centro de Ciencias Medioambientales C.S.I.C. Serrano 115 dpdo, E-28006, Madrid, Spain \\ ${ }^{6}$ Departamento de Biología y Geología, Escuela Superior de Ciencias Experimentales y Tecnológicas, Universidad Rey Juan Carlos, \\ c/ Tulipán s/n, E28933 Móstoles, Spain
}

(Received 29 December 2007; accepted 19 April 2008)

\begin{abstract}
-
- Interspecific differences in tree growth patterns with respect to biotic and abiotic factors are key for understanding forest structure and dynamics, and predicting potential changes under climate change.

- Repeated observations from the Spanish Forest Inventory (SFI) were used to parameterize maximum likelihood estimators of tree growth as a function of tree size, competition indices and climate for Pinus pinaster, P. sylvestris, Quercus ilex and Q. pyrenaica.

- Significant responses to both biotic and abiotic factors were found, with interspecific differences in species performance along competition, temperature and precipitation gradients. $Q$. ilex was the species most tolerant to competition while $P$. pinaster was the species most sensitive to climatic variation. Species relative positions shifted along gradients of these factors with rank reversals in species performance along size, competition and climatic gradients.

- The results based on average growth matched previous forestry classifications and experimental studies on relative growth rate (RGR).

- When examining growth along studied abiotic and biotic gradients, a mismatch was found between species performance ranks as predicted by our models and information derived from previous knowledge. Those discrepancies highlight the relevance of ontogeny and environmental heterogeneity in defining species performance along competition gradients.
\end{abstract}

niche differentiation / Pinus pinaster / Pinus sylvestris / Quercus ilex / Quercus pyrenaica

Résumé - Interversion de rangs dans la croissance des arbres en relation avec la taille de l'arbre, la compétition et les gradients climatiques pour quatre espèces forestières dominantes dans la canopée.

- Les différences interspécifiques dans les modèles de croissance des arbres, pour ce qui concerne les facteurs biotiques et abiotiques, sont des clés pour la compréhension des structures et des dynamiques forestières, et pour prédire les changement potentiels avec le changement climatique.

- Des observations répétées de l'Inventaire Forestier Espagnol (SFI) ont été utilisées pour paramétrer les estimateurs de probabilité maximum de croissance des arbres comme une fonction de la taille de l'arbre, des indices de compétition et du climat pour Pinus pinaster, Pinus sylvestris, Quercus ilex et Quercus pyrenaica.

- Des réponses significatives aux facteurs biotiques et abiotiques ont été trouvées, avec des différences interspécifiques pour les performances des espèces en relation avec la compétition, les gradients de température et de précipitations. Quercus ilex a été l'espèce la plus tolérante à la compétition tandis que Pinus pinaster a été l'espèce la plus sensible aux variations climatiques. Les positions relatives des espèces ont changé en relation avec les gradients de ces facteurs avec des interversions de rang pour les performances des espèces en relation avec la taille, la compétition et les gradients climatiques.

- Les résultats basés sur la moyenne de croissance sont en adéquation avec la classification forestière antérieure et les études expérimentales sur le taux relatif de croissance (RGR).

- En examinant la croissance en relations avec les gradients biotiques et abiotiques étudiés, il a été trouvé une disparité entre les rangs de performance des espèces prédits par nos modèles et les informations provenant des connaissances antérieures. Ces divergences soulignent l'importance de l'ontogénie et de l'hétérogénéité environnementale pour la détermination des performances des espèces en relation avec les gradients de compétition.

niche de différenciation / Pinus pinaster / Pinus sylvestris / Quercus ilex / Quercus pyrenaica

\footnotetext{
* Supplementary material (Tables and Figures) are available online only at www.afs-journal.org

**Corresponding author: zavala.miguel@inia.es
}

\section{INTRODUCTION}

Interspecific differences in tree growth are considered among the key factors driving forest succession, along with 
other processes such as mortality and seedling recruitment (Huston and Smith, 1987; Shugart, 1984). Tree growth is determined by the availability of resources, the current state of the tree and the tree's genetic background. Important resources influencing growth are light, water, $\mathrm{CO}_{2}$, nutrient availability and temperature (Lambers et al., 1998). Climate influences the spatial and temporal availability of these resources, particularly through direct effects on water availability and temperature (e.g. Lough, 1997; Varis et al., 2004). Competition between trees affects resource availability (Tilman, 1982), and therefore tree growth. Tree growth varies also with age and size since increasing size affects the ability of an individual to acquire resources (Wyckoff and Clark, 2005).

Despite the extensive literature on dendroecology (e.g. Andreu et al., 2007; Cherubini et al., 2003) and physiological mechanisms linked to tree growth (e.g. Montgomery, 2004; Pereira, 1994) the causes and community-level consequences of interspecific variation in tree growth remain poorly understood, even for many canopy dominant species. Chiefly, interspecific differences found on physiological- or morphological-level may not translate into divergence in whole-plant performance (Givnish, 1988). Moreover individual species variation can change along climatic and competition gradients (Begon et al., 1996; Whittaker, 1975), and ontogeny (Coleman et al., 1994), resulting in rank reversals in species performance along environmental gradients (Baraloto et al., 2005; Chesson, 1985). Those rank reversals are the key for understanding and identifying potential trade-offs which establish the functional basis for niche differentiation and species coexistence (Kitajima and Poorter, 2008). In other words, rank reversals in species performance along environmental gradients provide important clues to understand forest structure and dynamics along environmental gradients.

Traditionally, lack of individual species performance data has hampered the development and application of mechanistic theories of forest dynamics which often rely on intensive and detailed field data costly to obtain (Pacala et al., 1996). Recent availability of extensive data sets on tree distribution and performance along with numerically intensive statistical tools for model parameterization offer currently new avenues for multi-species comparison.

In this study, we analyzed data from the Spanish Forest Inventory (hereafter SFI) (DGCN, 2004; ICONA, 1994) to parameterize models of tree growth as a function of tree size, climatic variation and tree competition in central Spain. In the current context this approach is preferred over whole stand models because it allows describing the behavior of the stand or the community in terms of individual tree performance which is useful both from a theoretical (e.g. Levin, 1992; Zavala et al., 2007) and an applied perspective (Pukkala and Kolström, 1988).

In our study area, a sharp climatic gradient (reflected in the transition from Mediterranean to mesic or montane forests) occurs within approximately $50 \mathrm{~km}$. The overstory of these forests is dominated by four species, Quercus ilex L. spp. ballota (holm-oak), Q. pyrenaica Willd. (sessile oak), P. pinaster Ait. (maritime pine), Pinus sylvestris L. (Scots

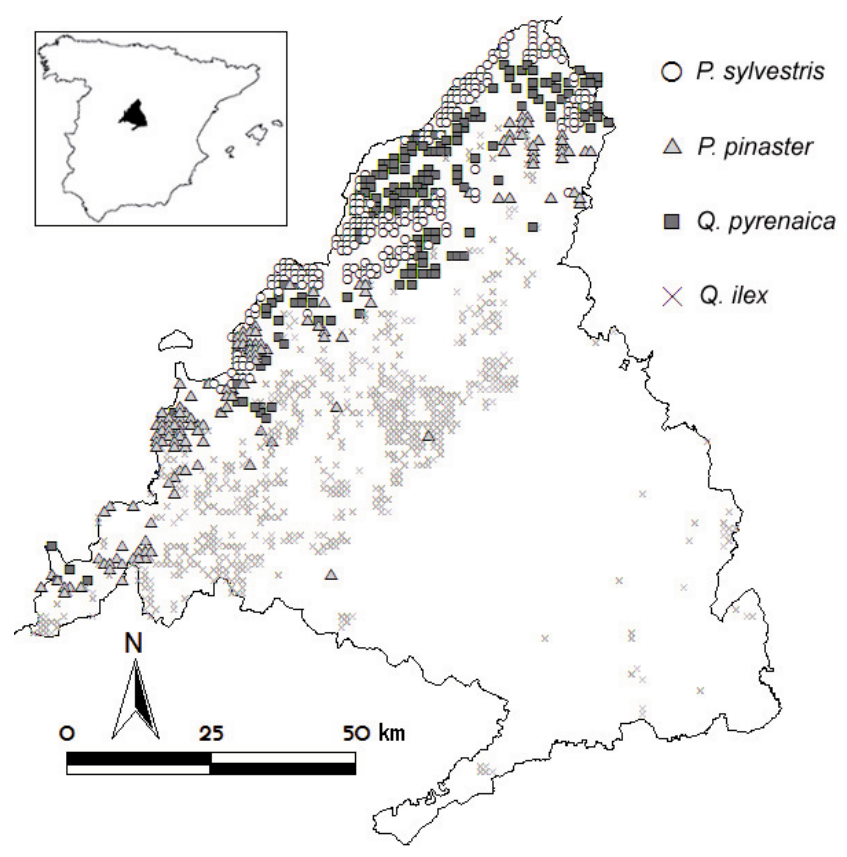

Figure 1. Map of the study region (province of Madrid, central Spain) including the distribution of the target species based on the SFI plots.

pine), which are representative of Mediterranean and montane forests throughout the Iberian Peninsula (Costa et al., 1998).

First, we tested a number of functional responses and independent variables to investigate the main factors (chiefly initial size, competition intensity and the climatic factors temperature and precipitation) influencing tree growth. Second, we tested for the existence of interspecific differences in tree growth along these biotic and abiotic factors and examine the agreement with previous qualitative forestry classifications and experimental data. Finally, we tested for the existence of rank reversals in tree growth along these factors.

\section{MATERIALS AND METHODS}

\subsection{Study region and species}

The study site comprises Madrid autonomous region located in the centre of the Iberian Peninsula (Fig. 1). It covers a surface area of $8028 \mathrm{~km}^{2}$, approximately $1.6 \%$ of Spain's total territory. This region spans $39^{\circ} 53^{\prime} \mathrm{N}$ to $41^{\circ} 10^{\prime} \mathrm{N}$ and $3^{\circ} 03^{\prime} \mathrm{W}$ to $4^{\circ} 34^{\prime} \mathrm{W}$, encompassing an altitudinal gradient that ranges from $470-2400 \mathrm{~m}$. The climate is quite variable with mean annual precipitation ranging from $300 \mathrm{~mm}$ to $1900 \mathrm{~mm}$, warm summers (average July temperature: 14 to $24^{\circ} \mathrm{C}$ ) and fairly cold winters (average January temperature: -1 to $6{ }^{\circ} \mathrm{C}$ ). The landscape is a mosaic of semi natural forests, savannas, shrublands, grasslands, intensive agricultural fields and urban areas (Purves et al., 2007).

The target species dominate the forest overstory throughout the Iberian Peninsula and are found in more than $85 \%$ of the forest stands in this region (DGCN, 2004). P. pinaster, Q. ilex and Q. pyrenaica have a typical Mediterranean distribution while $P$. sylvestris 
has a wider distribution along the Eurosiberian region also including the Mediterranean Basin (Costa et al., 1998). Q. ilex is a sclerophyllous Mediterranean oak more drought tolerant than $Q$. pyrenaica which has been classified as a nemoro-Mediterranean oak (Corcuera et al., 2002). P. pinaster is considered more drought tolerant than $P$. sylvestris. The former grows in montane areas with irregular precipitation and high temperatures in summer, while the latter is frequently found at a higher altitude mainly in northern aspects, with higher precipitation and mild temperatures (Bravo-Oviedo et al., 2006). The spatial distribution of these species in the study region is represented in Figure 1.

\subsection{Data collection and processing}

The SFI consists of a systematic sampling of permanent plots distributed on a square grid of $1 \mathrm{~km}$ onto forest areas, with a remeasurement interval of 10-years approximately. Plots were circular, of four concentric radii. Inclusion of a tree in the sample was function of its diameter at breast height (dbh, $1.3 \mathrm{~m}$ ), and its distance from the centre of the plot: $5 \mathrm{~m}$ radius was used for trees with dbh between $7.5-12.49 \mathrm{~cm} ; 10 \mathrm{~m}$ for $12.5-22.49 \mathrm{~cm} ; 15 \mathrm{~m}$ for $22.5-42.49 \mathrm{~cm}$; and $25 \mathrm{~m}$ for $\mathrm{dbh} \geqslant 42.5 \mathrm{~cm}$. For the purpose of this study data have been obtained from the second (2-SFI) and third (3-SFI) inventories carried out in Madrid in the period 1994 to 2004. We first combined and filtered all data from 2-SFI and 3-SFI discarding those errors of negative diameter or height growth, or with changes in species identity. We extracted a number of variables from the combined database including two perpendicular values for $\mathrm{dbh}(\mathrm{mm})$, tree height $(\mathrm{m})$ and UTM coordinates. Climatic data such as annual mean temperature $\left({ }^{\circ} \mathrm{C}\right)$ and annual mean precipitation $(\mathrm{mm})$ were provided by the Spanish Institute of Meteorology, as an interpolation of the information recorded in meteorological stations from 1971 to 2000 with $1 \mathrm{~km}$ spatial resolution (INM unpublished). Individual tree basal area was calculated as:

$$
B=\frac{\pi}{4} \cdot d_{1} \cdot d_{2}
$$

where $B$ stands for basal area $\left(\mathrm{cm}^{2}\right)$ and ' $d_{1}, d_{2}$ ' for the two perpendicular stem diameters $(\mathrm{cm})$ at breast height. Because of the particular sampling method of the SFI based on variable-radius concentric plots, the basal area was scaled up to a one-hectare area. Basal area growth was calculated as:

$$
\Delta B=B_{S F I-3}-B_{S F I-2}
$$

where $B_{S F I-3}$ and $B_{S F I-2}$ stand for basal area in the third SFI and the second SFI respectively.

We only selected those inventory plots where one of the four studied species, contributed at least to $95 \%$ of the total basal area of the plot. Such 'monospecific' stands for these species represent more than $86 \%$ of all the inventory plots in this region (i.e., 1180 plots) accounting for a total of 8010 individuals (1870 individuals for $Q$. ilex, 1,069 for $Q$. pyrenaica, 3,556 for $P$. sylvestris and 1515 for $P$. pinaster).

A number of distance-independent competition indices were also calculated that estimated the competition intensity on the subject tree as the total density or basal area of neighbouring trees per hectare. Half of these indices were one-sided competition indices that took into account only taller trees than the subject tree, while two-sided competition indices considered all neighbours and excluded the subject tree for calculations (see a full description of competition indices in Tab. I).

\subsection{Model formulation and comparison}

We modeled individual basal area growth for each of the four studied species. A gamma error distribution of basal area was assumed as it captured the whole range of variation observed in tree growth distributions. This distribution is defined by a scale parameter $a$ and a shape parameter $n$ that measures left-skewness. We specified the mean of the gamma distribution $(a \times n)$ as a function of initial size $(S$, as the basal area in 2-SFI), competition $(C$, as the value of a competition index), mean annual temperature $(T)$ and mean annual precipitation $(P)$. Other climatic predictors such as aridity indices (Dantin and Revenga, 1940; De Martonne, 1926) were first considered but they systematically rendered poorer fits to the growth models and were therefore not included in the final model. We tested different functional forms that covered a wide range of possible responses: linear, Michaelis Menten-type, power, exponential and hyperbolic. They were separately tested for each competition index. The models presented here (Tab. II) are just a representative sample of the various combinations that were evaluated. Specifically, we report models that resulted in the best fit within each functional form tested. Since the scale resolution of the models is defined by the plot $\left(1 \mathrm{~km}^{2}\right)$, independence of trees within the same plot is assumed.

Models were parameterized using a simulating annealing algorithm (Metropolis et al., 1953), and compared by likelihood (Edwards, 1992) and differences in Akaike's Information Criteria ( $\triangle \mathrm{AIC}$ ), which is defined for each $\mathrm{Model}_{i}$ as: $\mathrm{AIC}_{i}-\mathrm{AIC}$ minimum (Akaike, 1992). Models with $\triangle \mathrm{AIC}$ of $0-2$ were considered to have equivalent and substantial empirical support, $\triangle \mathrm{AIC}$ of 4-7 indicated less support and models with $\triangle \mathrm{AIC}>10$ had very low empirical support (Burnham and Anderson, 2002). In order to better interpret the relative likelihood of a model, given the data and the set of candidate models, we used Akaike weights $\left(\mathrm{w}_{i}\right)$ calculated as described by Burnham (Burnham and Anderson, 2002). Akaike weights provide the weight of evidence in favour of model $i$ being the actual best model for the situation at hand, assuming that one of the $N$ models tested must be the best model of that set of $N$ models. We also computed $95 \%$ support regions which were estimated by likelihood profile (Hilborn and Mangel, 1997). All models and numerical algorithms were implemented in $\mathrm{C}$ (Borland $\mathrm{C}++$ v.5.01, Borland International Inc., 1996). Finally, we calculated Moran's I autocorrelation coefficient for each species across distance classes for the best model residuals using GS + 5.1.1. (Gamma Design Software, Michigan, USA, 2001) to detect potential patterns of spatial autocorrelation not explained by the models.

\section{RESULTS}

\subsection{Factors influencing tree growth}

A number of alternative models differing in complexity and number of factors were evaluated. Model VIII (see Tab. II), which includes an initial size, a competition and a temperature and precipitation related influence on tree growth, resulted in the best fits for all the species (Suppl. Tab. A). Other models, such as models VI and VII had less empirical support while the rest had very low empirical support (see $\triangle$ AIC values in Suppl. Tab. A). Comparison between observed growth distributions and predicted growth distributions (given by the best 
Table I. Calculated competition indices and description.

\begin{tabular}{|c|c|c|}
\hline Competition index & Index symmetry & Description \\
\hline$D E N S=\sum_{j=1}^{n} j$ & Two-sided & Density of all competitor trees $j$ within the plot scaled up to a 1-ha area \\
\hline DENS high $=\sum_{\substack{j=1 \\
h_{j}>h_{i}}}^{n} j$ & One-sided & $\begin{array}{l}\text { Density of all competitor trees } j \text { within the plot with height } h \text { greater than that of the } \\
\text { subject tree } i \text { and scaled up to a 1-ha area }\end{array}$ \\
\hline$B A T=\sum_{j=1}^{n} B_{j}$ & Two-sided & Total basal area $B$ of competitor trees $j$ within the plot scaled up to a 1-ha area \\
\hline relBAT $=\sum_{j=1}^{n} \frac{B_{j}}{B_{i}}$ & Two-sided & $\begin{array}{l}\text { Total basal area } B \text { of competitor trees } j \text { within the plot relative to the total basal area } B \text { of } \\
\text { subject tree } i \text { scaled up to a 1-ha area }\end{array}$ \\
\hline relBAThigh $=\sum_{\substack{j=1 \\
h_{j}>h_{i}}}^{n} \frac{B_{j}}{B_{i}}$ & One-sided & $\begin{array}{l}\text { Total basal area } B \text { of competitor trees } j \text { within the plot relative to the total basal area } B \text { of } \\
\text { the subject tree } i \text { considering those competitor trees } j \text { with height } h \text { greater than that of } \\
\text { the subject tree } i \text { and scaled up to a 1-ha area }\end{array}$ \\
\hline
\end{tabular}

Table II. Functional forms and description of tested models.

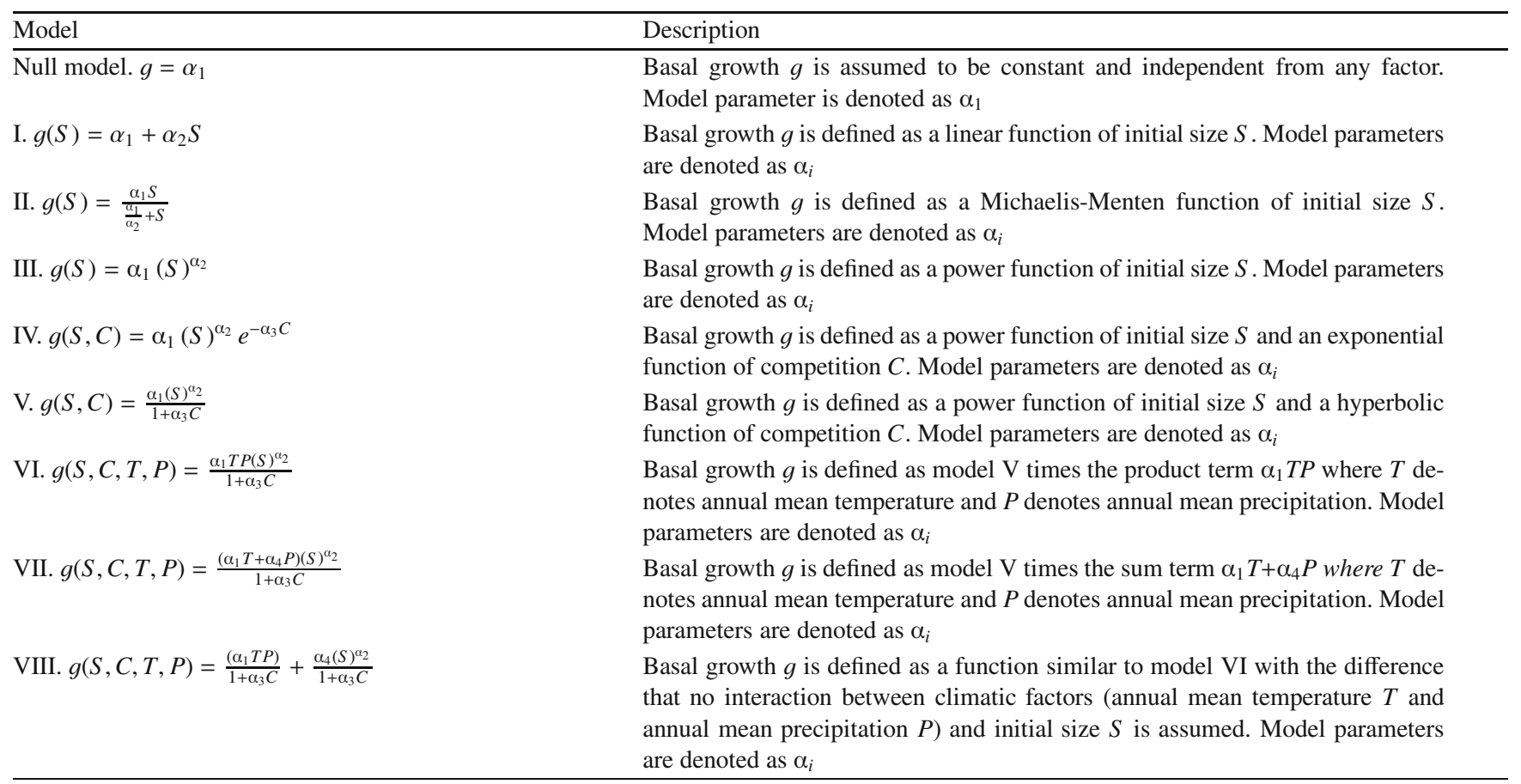

Model parameters $\left(\alpha_{i}\right)$ can be easily interpreted in biological terms. For example for model VIII, $\alpha_{1}$ estimates growth sensitivity to changes in the climatic factors (i.e. simplified as annual mean temperature and annual mean precipitation). Growth sensitivity to competition is estimated by $\alpha_{3}$. Finally the combination of $\alpha_{2}$ and $\alpha_{4}$ estimates the initial size-dependent component in the growth of each species. Thus increasing values of $\alpha_{i}$ denote increasing dependency on- or sensitivity to the corresponding factor.

model VIII) denoted a good fit of the model to the set of observations for each species (Suppl. Fig. A). Moreover, analyses of residuals showed a balanced pattern with respect to independent factors (Suppl. Fig. B). Moran's I correlograms showed a spatial-independent pattern of best model residuals for $Q$. ilex and $P$. pinaster. In contrast, a spatial-dependent pattern was detected for $Q$. pyrenaica and $P$. sylvestris (Suppl. Fig. C). For the last two species, additional factors accounting for spatial variability due, for example, to altitudinal gradients or patchy distributions should be considered in future studies.

All factors included in model VIII (initial size, competition and climatic factors) significantly (i.e., parameter values for these factors were significantly different from zero) explained individual variation in basal area growth for all the species but $Q$. pyrenaica (Suppl. Tab. A). For this species, the influence of climatic factors (i.e. the product between annual mean 
temperature $-T$ - and annual mean precipitation $-P-$ ) on basal area growth was not supported by the data (estimation of model VIII's parameter for the effect of climatic factors equalled zero, Suppl. Tab. A); but taking into account initial size and competition did result in a better description of the data.

Further differences among species were found. For example, relBAT (see indices' descriptions in Tab. I) was the competition index that resulted in the best fits for $Q$. pyrenaica, $P$. sylvestris and $P$. pinaster while BAT was the best predictor of competition for $Q$. ilex (Suppl. Tab. B).

\subsection{Interspecific differences along factors}

The same model (VIII) and the same competition index (relBAT) were used to evaluate interspecific differences in model parameters. Parameter values for each species' best model and 95\% confidence intervals are provided in Table III. The species ranking for $\alpha_{1}$ (see parameters' descriptions in Tab. II) values was: $P$. pinaster $>P$. sylvestris $>Q$. ilex $>Q$. pyrenaica. The ranking for $\alpha_{3}$ was: ( $P$. pinaster $\geq$ $P$. sylvestris) $\geq Q$. pyrenaica ) $>Q$. ilex. Parameters $\alpha_{2}$ and $\alpha_{4}$ can only be compared jointly, since their dimensions depend on one another (Fig. 4).

A functional interpretation (see Tab. II for a biological interpretation of models' parameters) of species ranks translates into the following results: $Q$. ilex was the species most tolerant to competition, followed in decreasing order by $Q$. pyrenaica, $P$. sylvestris and $P$. pinaster. However, the latter three species did not differ significantly in their tolerance to competition. $P$. pinaster was the species that exhibited the highest sensitivity to climatic factors, followed in decreasing order by $P$. sylvestris, $Q$. ilex and $Q$. pyrenaica. Given that growth dependency on initial size was defined by two parameters in model VIII, interspecific differences cannot be grasped by a simple linear pattern (Fig. 2). For initial size values lower than $500 \mathrm{~cm}^{2}, P$. sylvestris was the species with the highest initial size-dependent growth followed by $Q$. pyrenaica, $Q$. ilex and $P$. pinaster. However, initial size-dependent growth changed as initial size increased. For initial size values higher than $500 \mathrm{~cm}^{2}, Q$. pyrenaica was the species with the highest initial size-dependent growth, followed by $P$. sylvestris, $Q$. ilex and $P$. pinaster (Fig. 2).

\subsection{Rank reversals}

In general, pines exhibited higher growth than oaks. $P$. pinaster had the highest average growth followed in decreasing order by $P$. sylvestris, $Q$. pyrenaica and $Q$. ilex (Fig. 3) However, tree growth changed depending on initial size, competition intensity and climatic factors, and rank reversals in species growth were observed along variation in each factor (Fig. 4). For example, under xeric conditions (i.e. $T=14{ }^{\circ} \mathrm{C}$ and $P=450 \mathrm{~mm}$ ) and for low initial size (i.e. $200 \mathrm{~cm}^{2}$ ), species growth ranking was: $P$. sylvestris $>P$. pinaster $>Q$. pyrenaica $>Q$. ilex (Fig. 4a). For the same xeric conditions

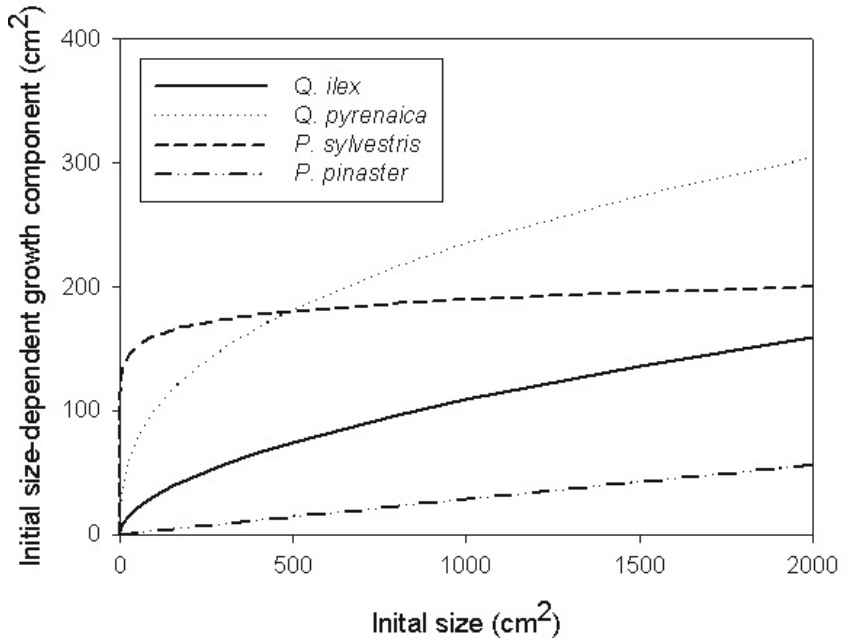

Figure 2. Initial size-dependent growth component for the studied species defined as: $\alpha_{4}(S)^{\alpha_{2}}$ where $\alpha_{i}$ denotes species specific parameters and $S$ denotes initial size. The estimates of parameters $\alpha_{4}$ and $\alpha_{2}$ for each species were obtained for fitted model VIII with relBAT as competition index, according to best model fits.

but higher initial size (i.e. $2000 \mathrm{~cm}^{2}$ ), however, species ranking changed along the competition gradient and species shifts were observed (Fig. 4b). In particular, Q. ilex was the species with the lowest growth rates for values of competition intensity below 500. For competition values between approx 500 and 1300 , it ranked second after $Q$. pyrenaica, while for competition values higher than 1300 , it ranked first. $Q$. pyrenaica ranked first when competition intensity was lower than approximately 1000 . Under mesic conditions (i.e. $T=7{ }^{\circ} \mathrm{C}$ and $P=1300 \mathrm{~mm}$ ), species growth patterns were similar to those previously mentioned for both low and high initial size (Figs. 4c and 4d). However, for $P$. pinaster and $P$. sylvestris (the most sensitive species to climatic factors), these conditions pushed the lines upwards, which changed species growth ranking for high initial size (Fig. 4d). Under these mesic conditions and for high initial size, $P$. pinaster ranked first when competition intensity was lower than approximately 500. As found for xeric conditions, $Q$. ilex ranked first under high competition intensity.

\section{DISCUSSION}

\subsection{Factors influencing tree growth}

Tree size, competition and site variables that reflect different climatic conditions are recognized as key factors influencing tree growth (e.g. Adame et al., 2006; García-Abril et al., 2007; Hein and Dhote, 2006). In this study, tree size and competition were significant factors that explained tree growth for the studied species. Mean temperature and precipitation also influenced tree growth for most of the species. The magnitude of the effect of each factor on tree growth was species dependent, denoting interspecific differences in sensitivity to these 
Table III. Maximum likelihood parameter estimates $\left(\alpha_{i}\right)$ and $95 \%$ confidence intervals (C. int) for the best-fit models relating basal growth to a number of factors (i.e. annual mean temperature $-T-$, annual mean precipitation $-P-$, initial size $-S-$ and competition $-C-$ ). That competition index that resulted in the best fit for each species is also indicated.

\begin{tabular}{|c|c|c|c|c|c|c|}
\hline & Best Model & Best $C$ & $\alpha_{1}$ (\%95 C.int) & $\alpha_{2}(\% 95$ C.int $)$ & $\alpha_{3}$ (\%95 C.int) & $\alpha_{4}(\% 95$ C.int $)$ \\
\hline \multirow[t]{2}{*}{ Q. ilex } & VIII & $B A T$ & $5.0 \mathrm{E}-05$ & 0.52 & $3.4 \mathrm{E}-06$ & 3.91 \\
\hline & & & $(1.2 \mathrm{E}-05-6.0 \mathrm{E}-05)$ & $(0.49-0.54)$ & $(2.4 \mathrm{E}-06-4.5 \mathrm{E}-06)$ & $(3.48-4.63)$ \\
\hline \multirow[t]{2}{*}{ Q. pyrenaica } & VIII & relBAT & - & 0.37 & $1.2 \mathrm{E}-03$ & 18.19 \\
\hline & & & & $(0.33-0.47)$ & (1.0E-03-1.5E-03) & $(8.54-23.44)$ \\
\hline \multirow[t]{2}{*}{ P. sylvestris } & VIII & relBAT & $1.0 \mathrm{E}-02$ & 0.07 & $1.6 \mathrm{E}-03$ & 114.72 \\
\hline & & & (3.1E-03-1.7E-02) & $(0.02-0.13)$ & (1.4E-03-1.9E-03) & $(57.27-193.80)$ \\
\hline \multirow[t]{2}{*}{$P$. pinaster } & VIII & relBAT & $3.2 \mathrm{E}-02$ & 0.98 & $1.7 \mathrm{E}-03$ & 0.03 \\
\hline & & & $(2.8 \mathrm{E}-02-3.5 \mathrm{E}-02)$ & $(0.62-1.00)$ & (1.4E-03-2.1E-03) & $(0.01-0.05)$ \\
\hline
\end{tabular}

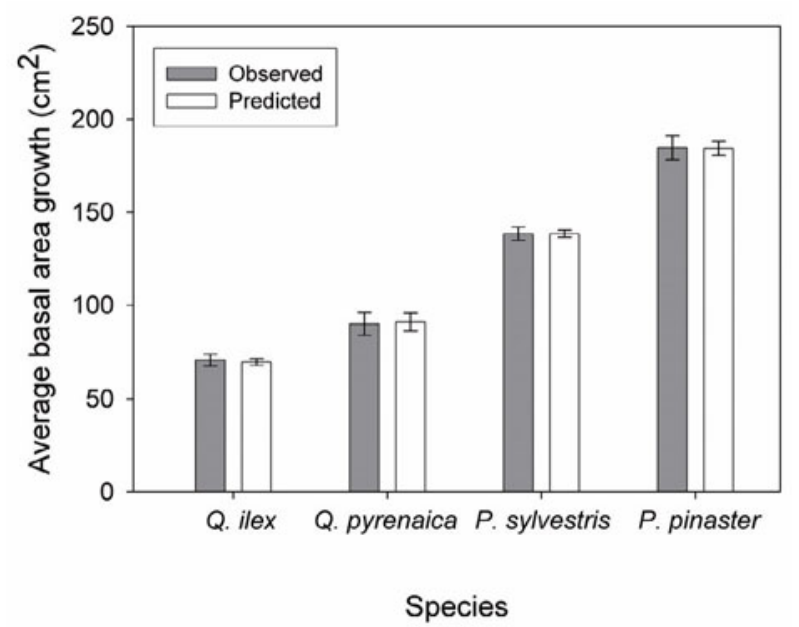

Figure 3. Observed and predicted mean basal area growth for the studied species. Error bars denote $95 \%$ confidence intervals of the mean.

factors. For $Q$. pyrenaica, tree size and competition but not climatic factors (mean temperature $\times$ mean precipitation) were significant determinants explaining most of the variability in growth. The main reason for the lack of influence of climatic factors on $Q$. pyrenaica's growth may be the narrower range of climatic conditions experienced by this species in the studied region as compared with the rest of species (Figs. 1 and 3 ). $Q$. pyrenaica is a species that exhibits however, a wider climatic range in other regions of Spain. For instance, in Castile and Leon, $Q$. pyrenaica occupies both Mediterranean and Temperate Submediterranean areas (del Río and Penas, 2006). Further research based on more extensive data sets including different regions are needed to get the whole climatic range of a species which is necessary for accurate predictions and interspecific comparisons at a regional scale.

\subsection{Interspecific differences along factors}

The higher average growth values exhibited by pines as compared with oaks agree with forestry knowledge in the
Iberian Peninsula (Ruiz de la Torre, 2001) and with other studies (Castro-Díez et al., 1998; Pausas et al., 2004; Zavala et al., 2000). Intra-genus differences in average growth also agreed with previous knowledge. For example, marcescent species $Q$. pyrenaica had higher average growth than evergreen $Q$. ilex in agreement with previously reported values for relative growth rate (RGR) of these species (Villar et al., 2004) and the fact that $Q$. pyrenaica occupies more mesic sites that the sclerophyllous $Q$. ilex. With regards to pines, we found the highest average growth in $P$. pinaster which is considered the fastest growing species among pines in the Iberian Peninsula (Ruiz de la Torre, 2001).

It is well known that species differ widely in RGR (Grime and Hunt, 1975). However, the actual growth exhibited by a single individual of a particular species will depend not only on its RGR, but also on the individual's position along the environmental gradient and finally on the individual's sensitivity to the factors defining the environmental gradient.

We found that $Q$. ilex was the species with the lowest sensitivity to competition and with the highest basal growth at high initial size and under high competition intensity of all examined species. This observation agrees with its late successional status (Broncano et al., 1998). Q. pyrenaica exhibited less basal growth at high initial size under high competition intensity than $Q$. ilex. However, its growth under such conditions was higher than those of pines (Figs. 4b and 4d) which still agrees with its late successional status (Gómez-Aparicio et al., 2006). In contrast, pines were most hampered in their growth by competition, in agreement with their shade intolerant early successional behaviour (Zavala and Zea, 2004). Pines also exhibited a higher sensitivity to climatic factors than oaks, which might be related to their higher phenotypic plasticity (Sánchez-Gómez et al., 2006a). However, such higher responsiveness to climatic factors did not make pines outperform oaks along the whole climatic gradient. Indeed, species ranking for tree growth changed along gradients of the studied factors. Thus, it cannot be argued that one species grows more than other without referring to a particular setting of environmental conditions. 


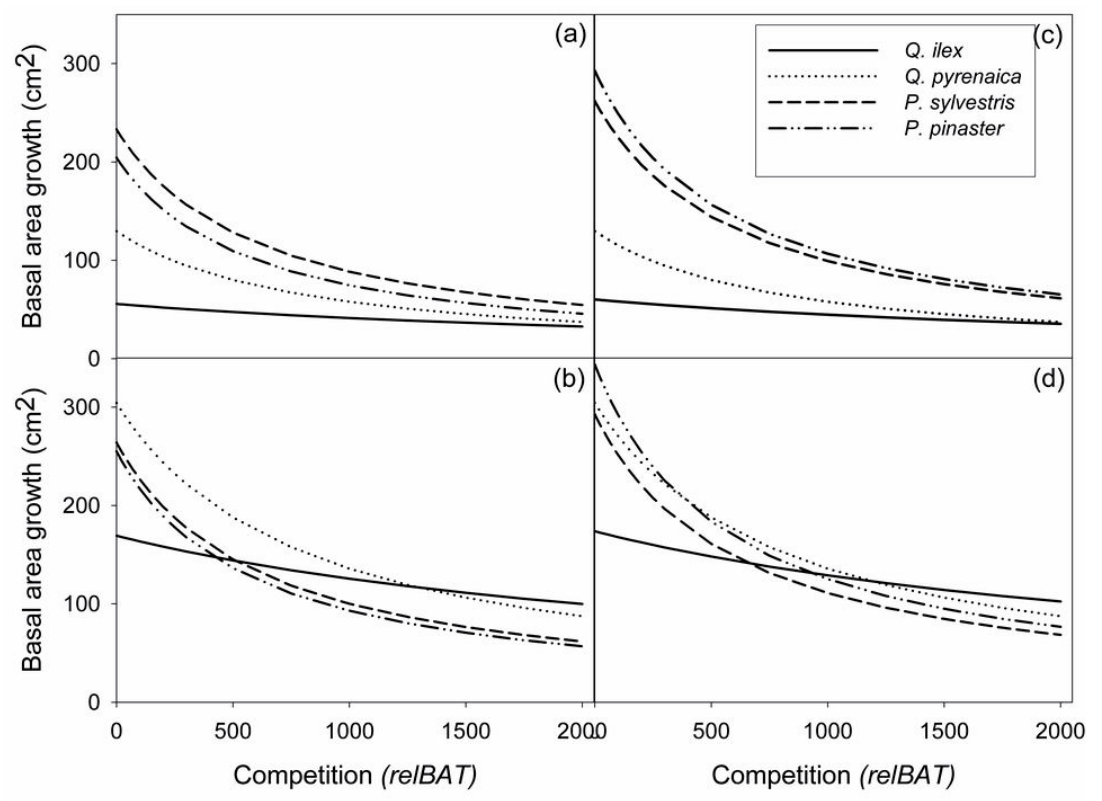

Figure 4. Basal growth against competition intensity. Model VIII and relBAT were chosen for comparison among species since they resulted in best model fits. Graph (a) represents values for fixed size of $200 \mathrm{~cm}^{2}$, annual mean temperature $(T)$ of $14{ }^{\circ} \mathrm{C}$ and annual mean precipitation $(P)$ of $450 \mathrm{~mm}$. Graph (b) represents values for fixed size of $2000 \mathrm{~cm}^{2}, T$ of $14{ }^{\circ} \mathrm{C}$ and $P$ of $450 \mathrm{~mm}$. Graph (c) represents values for fixed size of $200 \mathrm{~cm}^{2}, T$ of $7^{\circ} \mathrm{C}$ and $P$ of $1300 \mathrm{~mm}$. Graph (d) represents values for fixed size of $2000 \mathrm{~cm}^{2}, T$ of $7{ }^{\circ} \mathrm{C}$ and $P$ of $1300 \mathrm{~m}$.

\subsection{Rank reversals}

According to Poorter and Arets (2003), niche differentiation through resource partitioning requires the existence of a trade-off in species performance, in addition to the existence of a resource gradient and a differential species distribution along the gradient. Resource trade-offs can be tested through identification of rank reversals in species performance along the resource gradient (Baraloto et al., 2005). In this study, the axis of competition intensity can be considered as a gradient of resource depletion. The results showed that for early ontogenetic stages (low initial size values), differences between oaks and pines were bigger under mesic than under xeric conditions but no rank reversals were observed. In contrast, for higher initial size values rank reversals were observed. In general, pines performed best under low competition intensity, whilst oaks outperformed pines under high competition intensity. Among oaks, $Q$. ilex was the species with the highest growth under high competition intensity but the lowest growth under low competition intensity.

Several studies focusing on seedlings have failed to test the existence of growth trade-offs (Kitajima, 1994; Veneklaas and Poorter, 1998). The results of this study demonstrate that an appropriate test of trade-offs in species performance along resource gradients need to consider different ontogenetic stages, since expected trade-offs may not operate under early ontogenetic stages but may show up later. The reasons underlying tree performance changes with ontogeny include changes in absolute and relative growth, changes in biomass partitioning patterns and changes in shade and drought tolerance
(Cavender-Bares and Bazzaz, 2000; Sack and Grubb, 2001; Walters et al., 1993).

Another point that needs to be considered is the target variable used to test resource trade-offs. The lack of rank reversals on a growth basis does not imply that niche differentiation might occur through other performance variables. In fact, a previous study on survival revealed rank reversals between pines and oaks along an irradiance gradient at the very early seedling stage (Sánchez-Gómez et al., 2006b). Once different rank reversals and trade-offs at different levels have been identified, a key challenge remains to unveil the relative importance and the role played by these trade-offs and rank reversals in community assembly.

\subsection{Implications for forest management and for modelling community structure and dynamics}

The results derived from the models developed in this study have important implications for forest management. Two findings are of particular importance: (1) the impact of competition is species dependent and (2) different climatic conditions imply rank reversals in species growth, especially for mature individuals. These findings provide a scientific basis for understanding how management activities such as thinning (e.g. remove old or juvenile individuals, control of thinning intensity, etc.) might contribute to benefit some species at the expense of others under different climatic conditions. They may also contribute to understand species coexistence under future climatic conditions and might help to develop forestry policies and management guidelines for forest biodiversity preservation under climate change. 
Advances in analytical forest models (Kohyama, 1994; Zavala et al., 2007) suggest that ecological macroscopic processes such as stand structure and composition can be successfully described as a function of species-level information. Parameterization of species-specific models for growth, survival and recruitment are the first step towards the development of process-based models of forest dynamics that link whole-plant responses to patterns of community organization (Kohyama, 1994). The implementation of analytical models of forest dynamics that predict and explain community structure and dynamics under different disturbance/management regimes seems a feasible goal through a combined program of large scale data analyses, field work and modelling.

\subsection{Concluding remarks}

We found interspecific differences in tree growth for the four studied species along size, competition and climatic gradients. Species ranking by average growth agreed well with forestry knowledge and previous studies conducted in this region. However, observed rank reversals in species individual growth along gradients of tree size, competition and climatic factors denote the important role of ontogeny and environmental heterogeneity in explaining species-specific growth patterns. From this investigation, we obtain insights into tree growth that are critical for developing process-based models of forest dynamics in this region.

Acknowledgements: We thank Paloma Ruiz for her qualified help with the SFI database management and Silvia Matesanz for help with the analyses. DSG was supported by a grant from Comunidad de Madrid through the network REMEDINAL (S-0505/AMB/0335). IRU was supported by a FPI-MEC grant. MAZ acknowledges support from grants CAM-UAH2005/2004, REN2000-745 (CICYT) and CGL2005-05830-C03-01/BOS (CICYT). Interactions among scientists from CSIC and Universidad de Alcalá were facilitated by the forest research networks GLOBIMED (www.globimed.net) and REDBOME (www.redbome.org). DvS was facilitated by an Erasmus exchange grant.

\section{REFERENCES}

Adame P., Cañellas I., Roig S., and Del Río M., 2006. Modelling dominant height growth and site index curves for rebollo oak (Quercus pyrenaica Willd.). Ann. For. Sci 63: 929-940.

Akaike H., 1992. Information theory and an extension of the maximum likelihood principle. In: Kotz S. and Johnson N. (Eds.), Breakthroughs in statistics. Springer-Verlag, New York, pp. 610624.

Andreu L., Gutiérrez E., Macías M., Ribas M., Bosch O., and Camarero J.J., 2007. Climate increases regional tree-growth variability in Iberian pine forests. Glob. Change Biol. 13: 804-815.

Baraloto C., Goldberg D.E., and Bonal D., 2005. Performance trade-offs among tropical tree seedlings in contrasting microhabitats. Ecology 86: 2461-2472.

Begon M., Harper J.L., and Townsend C.R., 1996. Ecology: individuals, populations and communities. Blackwell Science Ltd, Oxford, GB.

Bravo-Oviedo A., Sterba H., del Rio M., and Bravo F., 2006. Competition-induced mortality for Mediterranean Pinus pinaster Ait. and P. sylvestris L. For. Ecol. Manage. 222: 88-98.
Broncano M.J., Riba M., and Retana J., 1998. Seed germination and seedling performance or two Mediterranean tree species, holm oak (Quercus ilex L.) and Aleppo pine (Pinus halepensis Mill.): a multifactor experimental approach. Plant Ecol. 138: 17-26.

Burnham K.P. and Anderson D.R., 2002. Model selection and multimodel inference:a practical information-theoretic approach. Springer-Verlag, New York.

Castro-Díez P., Puyravaud J.P., Cornelissen J.H.C., and Villar-Salvador P., 1998. Stem anatomy and relative growth rate in seedlings of a wide range of woody plant species and types. Oecologia 116: 57-66.

Cavender-Bares J. and Bazzaz F.A., 2000. Changes in drought response strategies with ontogeny in Quercus rubra: implications for scaling from seedlings to mature trees. Oecologia 124: 8-18.

Cherubini P., Gartner B.L., Tognetti R., Bräker O.U., Schoch W., and Innes J.L., 2003. Identification, measurement and interpretation of tree rings in woody species from Mediterranean climates. Biol. Rev. 78: 119-148.

Chesson P.L., 1985. Coexistence of competitors in spatially and temporally varying environments: a look at the combined effects of differents sorts of variability. Theor. Popul. Biol. 28: 263-287.

Coleman J.S., McConnaughay K.D.M., and Ackerly D.D., 1994. Interpreting phenotypic variation in plants. Trends Ecol. Evol. 9: 187-191.

Corcuera L., Camarcro J.J., and Pelegrín E.G., 2002. Funtional groups in Quercus species derived from the analysis of pressure-volume curves. Trees 16: 465-472.

Costa M., Morla C., and Sainz H., 1998. Los bosques ibéricos. Una interpretación geobotánica. Geoplaneta, Barcelona.

Dantin J. and Revenga A., 1940. Una nueva relación climatológica: el índice termopluviométrico. In: Avance al estudio de la aridez en España, Congreso de Zaragoza.

De Martonne E., 1926. L'indice d'aridité. Bull. Assoc. Géogr. Fr. 9: 3-5.

Del Río S. and Penas A., 2006. Potential distribution of semi-deciduous forest in Castile and Leon (Spain) in relation to climatic variations. Plant Ecol. 185: 269-282.

DGCN (Ed.), 2004. Tercer Inventario Forestal Nacional 1997-2006: Comunidad de Madrid. Ministerio de Medio Ambiente, Madrid.

Edwards A.W.F., 1992. Likelihood. John Hopkins University Press, Baltimore, MD.

García-Abril A., Martin-Fernández S., Grande M.A., and Manzaneda J.A., 2007. Stand structure, competition and growth of Scots pine (Pinus sylvestris L.) in a Mediterranean mountainous environment. Ann. For. Sci. 64: 825-830.

Givnish T.J., 1988. Adaptation to sun and shade: a whole-plant perspective. Aust. J. Plant Physiol. 15: 63-92.

Gómez-Aparicio L., Valladares F., Zamora R., 2006. Differential light responses of Mediterranean tree saplings: linking ecophysiology with regeneration niche in four co-occurring species. Tree Physiol. 26: 947-958.

Grime J.P., Hunt R., 1975. Relative growth rate: its range and adaptive significance in a local flora. J. Ecol. 63: 393-422.

Hein S. and Dhote J.F., 2006. Effect of species composition, stand density and site index on the basal area increment of oak trees (Quercus sp.) in mixed stands with beech (Fagus sylvatica L.) in northern France. Ann. For. Sci. 63: 457-467.

Hilborn R. and Mangel M., 1997. The ecological detective: confronting models with data. Princeton University Press, New Jersey.

Huston M. and Smith T., 1987. Plant succession: life history and competition. Am. Nat. 130: 168-198.

ICONA (Ed.), 1994. Segundo Inventario Forestal Nacional 1986-1995: Comunidad de Madrid. Ministerio de Medio Ambiente, Madrid. 
Kitajima K., 1994. Relative importance of photosynthetic traits and allocation patterns as correlates of seedling shade tolerance of 13 tropical trees. Oecologia 98: 419-428.

Kitajima K. and Poorter L., 2008. Functional basis for resource niche differentiation by tropical trees. In: Carson W.P. and Schnitzer S.A. (Eds.), Tropical forest community ecology. Blackwell (in press).

Kohyama T., 1994. Size-structure-based models of forest dynamics to interpret population- and community-level mechanisms. J. Plant Res. 107: $107-116$.

Lambers H., Chapin F.S. III, and Pons T.L., 1998. Plant physiological ecology. Springer-Verlag, York, PA.

Levin S.A., 1992. The problem of pattern and scale in ecology. Ecology 73: 1943-1967.

Lough J.M., 1997. Regional indices of climate variation: Temperature and rainfall in Queensland, Australia. Int. J. Climatol. 17: 55-66.

Metropolis N., Rusenbluth A.W., Rusenbluth M.N., Teller A.H., and Teller E., 1953. Equation of state calculations by fast computing machines. J. Chem. Phys. 21: 1087-1092.

Montgomery R., 2004. Relative importance of photosynthetic physiology and biomass allocation for tree seedling growth across a broad light gradient. Tree Physiol. 24: 155-167.

Pacala S.W., Canham C.D., Saponara J., Silander J.A., Kobe R.K.J., and Ribbens E., 1996. Forest models defined by field measurements: estimation, error analysis, and dynamics. Ecol. Monogr. 66: 1-43.

Pausas J.G., Bladé C., Valdecantos A., Seva J.P., Fuentes D., Alloza A., Vilagrosa A., Bautista S., Cortina J., and Vallejo R., 2004. Pines and oaks in the restoration of Mediterranean landscapes of Spain: new perspectives for and old practice - a review. Plant Ecol. 171: 209220.

Pereira J.S., 1994. Gas exchange and growth. In: Schulze E.D. and Caldwell M.M. (Eds.), Ecophysiology of photosynthesis. SpringerVerlag, New York.

Poorter L. and Arets E.J.M.M., 2003. Light environment and tree strategies in a Bolivian tropical moist forest: an evaluation of the light partitioning hypothesis. Plant Ecol. 166: 295-306.

Pukkala T. and Kolström T., 1988. Simulation of the development of Norway spruce stands using a transition matrix. For. Ecol. Manage. 25: $255-267$.

Purves D.W., Zavala M.A., Ogle K., Prieto F., and Rey Benayas J.M., 2007. Environmental heterogeneity, bird-mediated directed dispersal, and oak woodland dynamics in Mediterranean Spain. Ecol. Monogr. (in press).

Ruiz de la Torre J., 2001. Árboles y arbustos de la España peninsular. Fundación Conde del Valle de Salazar y Grupo Mundi-prensa, Madrid.
Sack L. and Grubb P.J., 2001. Why do species of woody seedlings change rank in relative growth rate between low and high irradiance? Funct. Ecol. 15: 145-154.

Sánchez-Gómez D., Valladares F., and Zavala M.A., 2006a. Functional traits and plasticity in response to light in seedlings of four Iberian forest tree species. Tree Physiol. 26: 1425-1433.

Sánchez-Gómez D., Zavala M.A., and Valladares F., 2006b. Seedling survival responses to irradiance are differentially influenced by lowwater availability in four tree species of the Iberian cool temperateMediterranean ecotone. Acta Oecol. 30: 322-332.

Shugart H.H., 1984. A theory of forest dynamics: the ecological implications of forest succession models. Springer-Verlag, New York.

Tilman D., 1982. Resource competition. Princeton University Press, Princeton, NJ.

Varis O., Kajander T., and Lemmela R., 2004. Climate and water: From climate models to water resources management and vice versa. Clim. Change 66: 321-344.

Veneklaas E.J. and Poorter L., 1998. Growth and carbon partitioning of tropical tree seedlings in contrasting light environments. In: Lambers H., Poorter H., and Van Vuuren M.M.I. (Eds.), Inherent variation in plant growth: physiological mechanisms and ecological consequences. Backhuys, Leiden, NL, pp. 337-361.

Villar R., Ruiz-Robleto J., Quero J.L., Poorter H., Valladares F., and Marañón T., 2004. Tasas de crecimiento en especies leñosas: aspectos funcionales e implicaciones ecológicas. In: Valladares $\mathrm{F}$. (Ed.), Ecología del bosque mediterráneo en un mundo cambiante. Ministerio de Medio Ambiente, EGRAF, S.A., Madrid, pp. 191-227.

Walters M.B., Kruger E.L., and Reich P.B., 1993. Growth, biomass distribution and $\mathrm{CO}_{2}$ exchange of northern hardwood seedling in high and low light: relationships with successional status and shade tolerance. Oecologia 94: 7-16.

Whittaker R.H., 1975. Communities and ecosystems. Macmillan, New York, USA.

Wyckoff P.H. and Clark J.S., 2005. Tree growth prediction using size and exposed crown area. Can. J. For. Res. 35: 13-20.

Zavala M.A. and Zea G.E., 2004. Mechanisms maintaining biodiversity in Mediterranean pine-oak forests: insights from a spatial simulation model. Plant Ecol. 171: 197-207.

Zavala M.A., Espelta J.M., and Retana J., 2000. Constraints and trade-offs in Mediterranean plant communities: the case of Holm oak-Aleppo pine forests. Bot. Rev. 66: 119-149.

Zavala M.A., Angulo O., Bravo de la Parra R., and López-Marcos J.C., 2007. An analytical model of stand dynamics as a function of tree growth, mortality and recruitment: The shade tolerance-stand structure hypothesis revisited. J. Theor. Biol. 244: 440-450. 


\section{Online Material}


Table A. Maximum likelihood parameter estimates for the models tested relating basal growth with a number of factors (i.e. annual mean temperature $-T-$, annual mean precipitation $-P-$, initial size $-S-$ and competition $-C-$ ). Model fits are evaluated through differences in AIC $(\triangle \mathrm{AIC})$ and Akaike weights $\left(\mathrm{w}_{i}\right)$. The competition index used to evaluate the best model was relBAT. The shape parameter of the gamma distribution is denoted as $n$. Model parameters are denoted as $\alpha_{i}$. The log-likelihood estimation is denoted as logLike.

\begin{tabular}{|c|c|c|c|c|c|c|c|c|c|c|}
\hline & Model (factors) & $n$ & $\alpha_{1}$ & $\alpha_{2}$ & $\alpha_{3}$ & $\alpha_{4}$ & logLike. & AIC & $\Delta \mathrm{AIC}$ & $\mathrm{w}_{i}$ \\
\hline \multirow{7}{*}{ Q. ilex } & $\mathrm{VIII}(S, C, T, P)$ & 1.93 & $1.6 \mathrm{E}-03$ & 0.54 & $3.5 \mathrm{E}-04$ & 2.55 & -11275.2 & 22560.4 & 0 & $2.2 \mathrm{E}+00$ \\
\hline & $\mathrm{VII}(S, C, T, P)$ & 1.91 & 0.18 & 0.47 & $2.5 \mathrm{E}-04$ & $3.9 \mathrm{E}-03$ & -11276.7 & 22563.4 & 3.1 & $1.7 \mathrm{E}-01$ \\
\hline & $\mathrm{V}(S, C)$ & 1.90 & 5.13 & 0.46 & $2.9 \mathrm{E}-04$ & & -11279.5 & 22567.0 & 6.6 & $2.6 \mathrm{E}-02$ \\
\hline & $\operatorname{IV}(S, C)$ & 1.90 & 4.59 & 0.47 & $1.8 \mathrm{E}-04$ & & -11282.2 & 22572.4 & 12.0 & $1.7 \mathrm{E}-03$ \\
\hline & $\mathrm{IIII}(S)$ & 1.89 & 3.27 & 0.52 & & & -11295.5 & 22597.0 & 36.7 & 7.4E-09 \\
\hline & $\mathrm{I}(S)$ & 1.80 & 27.02 & 0.10 & & & -11348.2 & 22702.4 & 142.0 & $1.0 \mathrm{E}-31$ \\
\hline & null & 1.24 & 70.91 & & & & -11859.7 & 23723.4 & 1163.1 & $1.9 \mathrm{E}-253$ \\
\hline \multirow{5}{*}{ Q. pyrenaica } & $\mathrm{VIII}(S, C, T, P)$ & 2.32 & 0 & 0.37 & $1.2 \mathrm{E}-03$ & 18.19 & -5365.4 & 10740.8 & 0 & $1.6 \mathrm{E}+02$ \\
\hline & $\mathrm{VI}(S, C, T, P)$ & 2.34 & $2.0 \mathrm{E}-03$ & 0.37 & $1.2 \mathrm{E}-03$ & & -5371.6 & 10751.3 & 10.5 & $5.2 \mathrm{E}-03$ \\
\hline & II $(S)$ & 1.85 & 367.02 & 0.52 & & & -5545.4 & 11096.8 & 356.0 & $4.9 \mathrm{E}-78$ \\
\hline & $\mathrm{I}(S)$ & 1.67 & 16.55 & 0.26 & & & -5571.8 & 11149.6 & 408.9 & $1.6 \mathrm{E}-89$ \\
\hline & null & 1.04 & 90.17 & & & & -5879.7 & 11763.5 & 1022.7 & 8.3E-223 \\
\hline \multirow{6}{*}{ P. sylvestris } & VIII $(S, C, T, P)$ & 2.26 & $1.0 \mathrm{E}-02$ & 0.07 & $1.6 \mathrm{E}-03$ & 114.72 & -25604.2 & 51236.2 & 0 & $8.7 \mathrm{E}+04$ \\
\hline & $\mathrm{V}(S, C)$ & 2.26 & 193.43 & 0.05 & $1.6 \mathrm{E}-03$ & & -25616.9 & 51241.7 & 23.3 & 8.7E-06 \\
\hline & $\mathrm{VI}(S, C, T, P)$ & 2.25 & $2.9 \mathrm{E}-02$ & $1.3 \mathrm{E}-02$ & $1.7 \mathrm{E}-03$ & & -25618.0 & 51244.1 & 25.6 & $2.8 \mathrm{E}-06$ \\
\hline & $\mathrm{VII}(S, C, T, P)$ & 2.25 & 5.99 & 0.14 & $1.1 \mathrm{E}-03$ & 4.7E-02 & -25622.1 & 51254.1 & 35.7 & $1.8 \mathrm{E}-08$ \\
\hline & $\mathrm{IV}(S, C)$ & 2.19 & 63.82 & 0.18 & 4.3E-04 & & -25671.5 & 51351.0 & 132.6 & $1.6 \mathrm{E}-29$ \\
\hline & $\mathrm{III}(S)$ & 1.91 & 10.05 & 0.43 & & & -26045.2 & 52096.4 & 878.0 & 2.2E-191 \\
\hline \multirow{6}{*}{ P. pinaster } & $\mathrm{V}(S, C)$ & 2.20 & 191.31 & 0.08 & $1.7 \mathrm{E}-03$ & & -10878.0 & 21764.1 & 47.1 & $4.8 \mathrm{E}-11$ \\
\hline & $\mathrm{IV}(S, C)$ & 2.14 & 70.46 & 0.19 & 4.4E-04 & & -10910.2 & 21828.5 & 111.5 & $5.0 \mathrm{E}-25$ \\
\hline & $\mathrm{III}(S)$ & 1.82 & 14.54 & 0.40 & & & -11077.5 & 22161.0 & 444.1 & 3.0E-97 \\
\hline & $\mathrm{I}(S)$ & 1.84 & 96.68 & 0.12 & & & -11079.5 & 22165.1 & 448.2 & 3.9E-98 \\
\hline & II $(S)$ & 1.77 & 288.17 & 1.07 & & & -11113.0 & 22231.9 & 515.0 & $1.2 \mathrm{E}-112$ \\
\hline & null & 1.55 & 184.74 & & & & -11256.8 & 22517.6 & 800.6 & 1.2E-174 \\
\hline
\end{tabular}


Table B. Maximum likelihood parameter estimates for the best-fit models relating Basal growth with a number of factors (i.e. annual mean temperature $-T-$, annual mean precipitation $-P-$, initial size $-S$ - and competition $-C-$ ). All the competition indices studied are evaluated. Model fits are evaluated through differences in AIC $(\triangle \mathrm{AIC})$ and Akaike weights $\left(\mathrm{w}_{i}\right)$. The shape parameter of the gamma distribution is denoted as $n$. Model parameters are denoted as $\alpha_{i}$. The log-likelihood estimation is denoted as logLike.

\begin{tabular}{|c|c|c|c|c|c|c|c|c|c|c|c|}
\hline & Best Model & $C$ & $n$ & $\alpha_{1}$ & $\alpha_{2}$ & $\mathrm{~A}_{3}$ & $\alpha_{4}$ & logLike. & AIC & $\Delta \mathrm{AIC}$ & $\mathrm{w}_{i}$ \\
\hline \multirow{6}{*}{ Q. ilex } & \multirow{6}{*}{ VIII } & $B A T$ & 1.91 & $5.0 \mathrm{E}-05$ & 0.52 & $3.4 \mathrm{E}-06$ & 3.91 & -11271.2 & 22552.5 & 0 & $2.0 \mathrm{E}+01$ \\
\hline & & BAThigh & 1.92 & $1.3 \mathrm{E}-03$ & 0.59 & 4.3E-06 & 2.10 & -11274.8 & 22559.5 & 7.1 & $2.8 \mathrm{E}-02$ \\
\hline & & relBAT & 1.93 & $1.6 \mathrm{E}-03$ & 0.54 & $3.5 \mathrm{E}-04$ & 2.55 & -11275.2 & 22560.4 & 7.9 & $1.9 \mathrm{E}-02$ \\
\hline & & DENShigh & 1.91 & 9.4E-04 & 0.55 & 5.2E-04 & 2.58 & -11278.5 & 22567.0 & 14.5 & $6.8 \mathrm{E}-04$ \\
\hline & & relBAThigh & 1.90 & $1.5 \mathrm{E}-03$ & 0.57 & 3.9E-04 & 2.15 & -11278.8 & 22567.6 & 15.1 & $5.0 \mathrm{E}-04$ \\
\hline & & DENS & 1.89 & 7.1E-04 & 0.53 & $2.6 \mathrm{E}-04$ & 3.05 & -11280.3 & 22570.6 & 18.2 & 1.1E-04 \\
\hline \multirow{6}{*}{ Q. pyrenaica } & \multirow{6}{*}{ VIII } & relBAT & 2.32 & 0 & 0.37 & $1.2 \mathrm{E}-03$ & 18.19 & -5365.4 & 10740.8 & 0 & $5.2 \mathrm{E}+09$ \\
\hline & & relBAThigh & 2.24 & $2.1 \mathrm{E}-03$ & 0.51 & $1.3 \mathrm{E}-03$ & 5.64 & -5387.8 & 10785.5 & 44.8 & $1.9 \mathrm{E}-10$ \\
\hline & & DENShigh & 2.29 & 5.5E-04 & 0.53 & $1.9 \mathrm{E}-03$ & 5.85 & -5391.4 & 10792.7 & 51.9 & $5.4 \mathrm{E}-12$ \\
\hline & & $B A T$ & 2.20 & 0 & 0.70 & 8.6E-06 & 3.28 & -5396.4 & 10802.8 & 62.1 & 3.3E-14 \\
\hline & & BAThigh & 2.14 & 0 & 0.63 & 9.7E-06 & 3.76 & -5412.7 & 10835.4 & 94.7 & 2.7E-21 \\
\hline & & DENS & 2.12 & 0 & 0.56 & 7.7E-04 & 5.76 & -5418.2 & 10846.4 & 105.6 & $1.2 \mathrm{E}-23$ \\
\hline \multirow{6}{*}{ P. sylvestris } & \multirow{6}{*}{ VIII } & relBAT & 2.26 & $1.0 \mathrm{E}-02$ & 0.07 & $1.6 \mathrm{E}-03$ & 114.72 & -25604.2 & 51218.4 & 0 & $2.8 \mathrm{E}+42$ \\
\hline & & relBAThigh & 2.17 & $1.4 \mathrm{E}-02$ & 0.59 & $1.1 \mathrm{E}-03$ & 1.52 & -25702.0 & 51413.9 & 195.5 & $3.5 \mathrm{E}-43$ \\
\hline & & $B A T$ & 2.14 & 4.6E-03 & 0.60 & 4.3E-06 & 5.98 & -25761.3 & 51532.6 & 314.2 & 5.9E-69 \\
\hline & & BAThigh & 2.09 & $4.5 \mathrm{E}-03$ & 0.52 & $3.7 \mathrm{E}-06$ & 5.94 & -25793.0 & 51596.1 & 377.7 & $9.6 \mathrm{E}-83$ \\
\hline & & DENShigh & 2.08 & 7.9E-03 & 0.49 & $1.1 \mathrm{E}-03$ & 4.87 & -25834.7 & 51679.4 & 461.0 & 7.9E-101 \\
\hline & & DENS & 2.01 & $6.0 \mathrm{E}-03$ & 0.51 & 3.4E-04 & 5.11 & -25948.2 & 51906.5 & 688.1 & $3.8 \mathrm{E}-150$ \\
\hline \multirow{6}{*}{ P. pinaster } & \multirow{6}{*}{ VIII } & relBAT & 2.25 & $3.2 \mathrm{E}-02$ & 0.98 & $1.7 \mathrm{E}-03$ & 0.03 & -10853.5 & 21716.9 & 0 & $8.4 \mathrm{E}+10$ \\
\hline & & relBAThigh & 2.21 & 2.2E-02 & 1.00 & $1.7 \mathrm{E}-03$ & 0.06 & -10878.6 & 21767.2 & 50.3 & $1.2 \mathrm{E}-11$ \\
\hline & & $B A T$ & 2.15 & 8.7E-03 & 0.60 & $3.5 \mathrm{E}-06$ & 5.01 & -10918.7 & 21847.5 & 130.6 & 4.4E-29 \\
\hline & & DENShigh & 2.10 & $1.7 \mathrm{E}-02$ & 0.78 & $1.9 \mathrm{E}-03$ & 0.51 & -10930.2 & 21870.4 & 153.4 & 4.9E-34 \\
\hline & & BAThigh & 2.08 & $1.2 \mathrm{E}-02$ & 0.70 & 4.0E-06 & 1.43 & -10935.6 & 21881.2 & 164.3 & $2.1 \mathrm{E}-36$ \\
\hline & & DENS & 1.99 & $1.4 \mathrm{E}-02$ & 0.73 & $5.6 \mathrm{E}-04$ & 0.92 & -10996.8 & 22003.7 & 286.7 & $5.5 \mathrm{E}-63$ \\
\hline
\end{tabular}



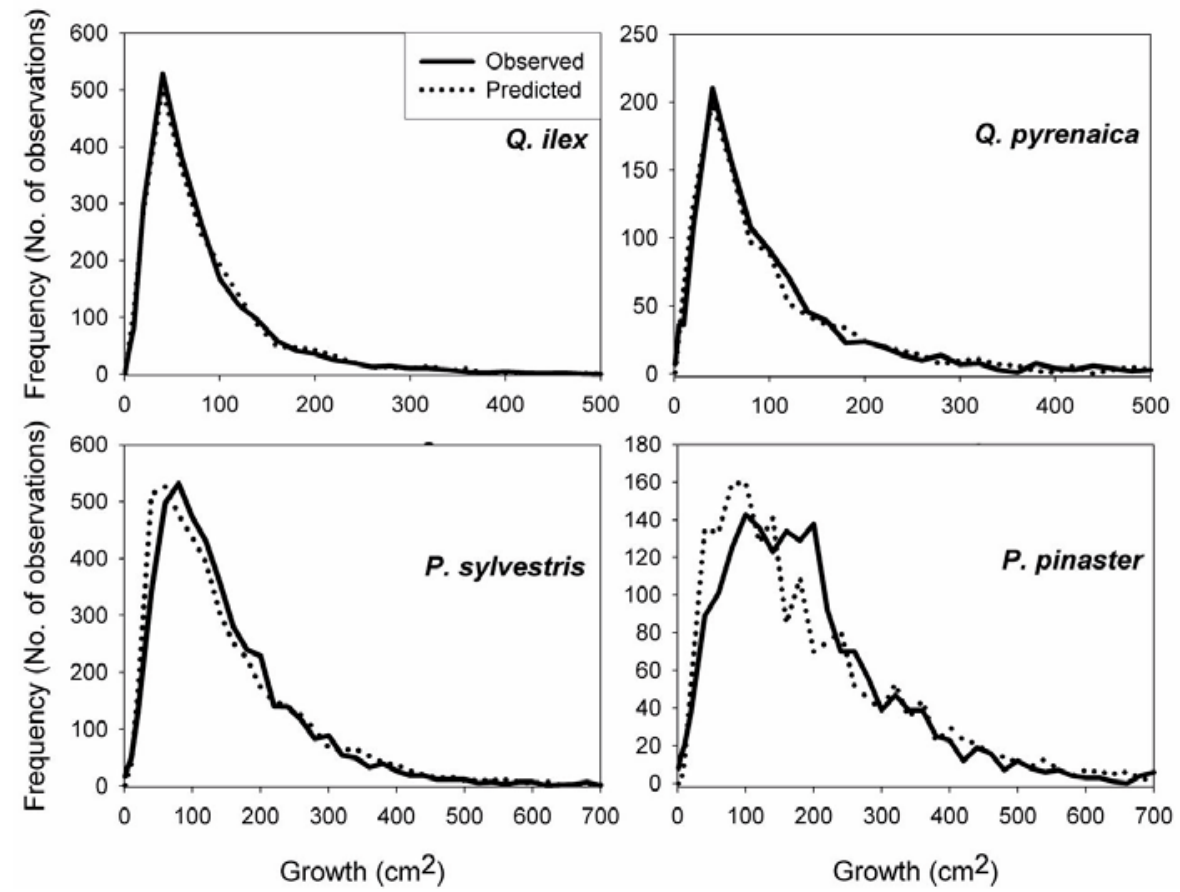

Figure A. Observed versus predicted growth distributions for each species. Predicted values were obtained from the models that resulted in the best fit for each species. 

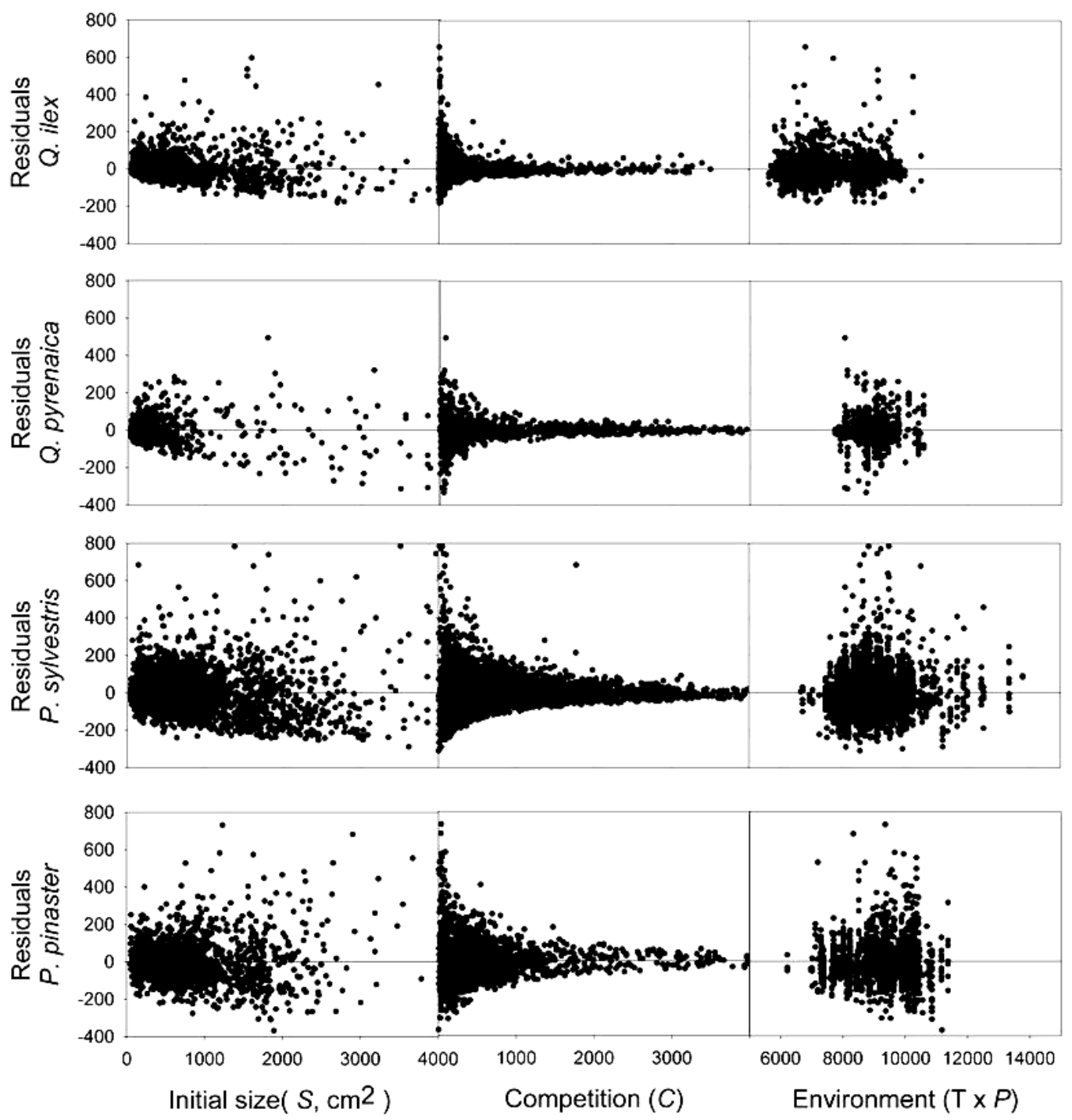

Figure B. Best model residuals against predictive factors for each species. BAT was the competition index $(C)$ considered for $Q$. ilex, while rel$B A T$ was considered for the rest of species according to best model fits. $T$ and $P$ denote annual mean temperature and annual mean precipitation respectively. 


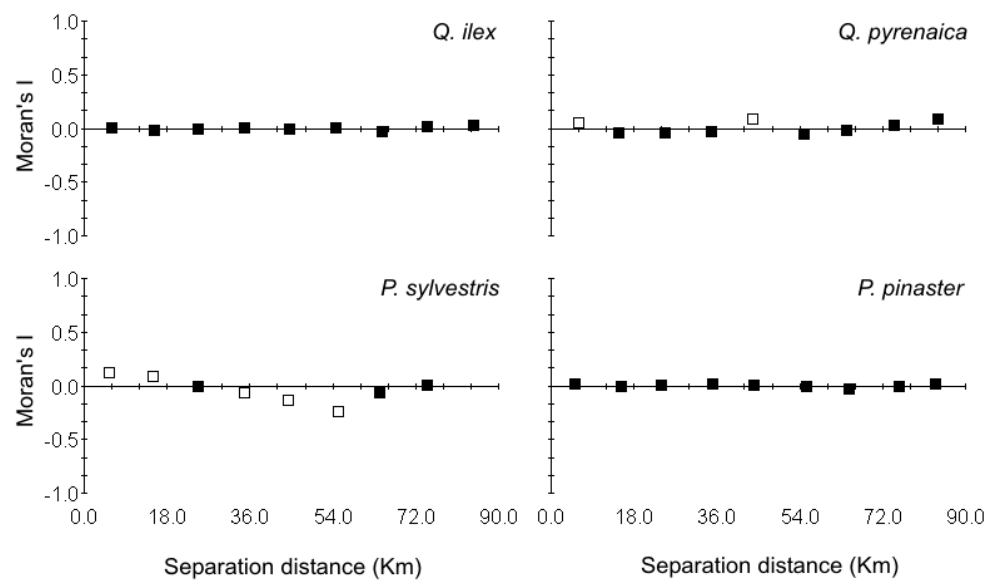

Figure C. Correlograms of Moran's I showing patterns of spatial autocorrelation of best model residuals for the four studied species. Open symbols denote significant Moran's I values for the corresponding distance class. Progressive Bonferroni correction was applied. 